\title{
Energy Analysis of End-of-life Options for Personal Computers: Resell, Upgrade, Recycle
}

\author{
Eric D. Williams \\ United Nations University \\ Tokyo, Japan \\ Email: Williams@hq.unu.edu
}

\author{
Yukihiro Sasaki \\ Mizuho Financial Group \\ Tokyo, Japan \\ Email: y-sasaki@pop06.odn.ne.jp
}

\begin{abstract}
Governments, firms, and civil society are increasingly taking action to mange the end-of-life of computers. While appropriate treatment of the waste stream via recycling and other technologies is required, it is also important to address the flow upstream through reduction of final demand via improved utilization. This article evaluates endof-life options for computers via quantitative assessment of life cycle energy use in three cases: reselling to secondary markets, upgrading of key components, and recycling to recover materials. Results indicate that reselling or upgrading $10 \%$ of end-of-life computers reduces life cycle energy use by $8.6 \%$ and $5.2 \%$ respectively. In contrast, recycling $10 \%$ of computers only saves $.43 \%$ of life cycle energy, suggesting that reselling and upgrading are far more effective from an environmental standpoint. The origin of this dramatic difference between reuse and recycling lies in the fact that much of the energy investment in the life cycle of a computer is in producing its complex form rather than its physical substance. Thus, the environmental payback of recycling materials is poor compared to many goods. This strongly suggests that management strategies for waste electronics should emphasize extension of lifespan.
\end{abstract}

\section{Keywords}

computers, resell, secondary markets, upgrade, recycling, energy, environment

\section{INTRODUCTION}

The question of how to deal with end-of-life personal computers (PCs) and other IT equipment is increasingly on the minds of those in governments, industry and the public at large. Much of the discussion and activities have focused on how PCs may be most efficiently collected and recycled. While recycling is clearly important, the traditional wisdom of waste management dictates that upstream management of wastes is as, if not more important, than final treatment. This idea has been codified in prioritization strategies such as "the 3Rs" (reduce, reuse, recycle).

Such strategies should also apply to IT equipment; indeed one can argue that there is even more potential in emphasizing upstream management than for many other goods. One reason is that most computers that are disposed of are still functional (though no longer attractive to the original user). The other reason is that a particularly high ratio of the environmental impacts of the computer life cycle occurs in the processing of materials and manufacture of parts, as opposed to the production of raw materials. Thus recycling of raw materials will not "refund" environmental impacts to near the extent that it does for simpler products such as aluminum cans and newspapers.

Upstream management of the computer waste stream is essentially about extending its usable lifespan. If computers are used longer, fewer new ones are needed and thus the future size of the waste stream is reduced. Extending lifespan can be done by delaying purchase of a new machine, reselling to secondary markets and upgrading. While the various actors dealing with waste electronics are certainly aware of these options, they have yet to be explicitly analyzed and aggressively pursued.

A first step is to clarify the importance of improved utilization through assessment of its environmental potential of compared to recycling. To this end, in this article we undertake a preliminary analysis of the relative effect of reselling, upgrading and recycling PCs on life cycle energy use. Energy use is, of course, not the only environmental issue associated with the life cycle of a computer. However, when comparing options that affect the overall consumption of a good, all environmental burdens are linked to a certain degree. In short, a savings in energy reflects production of fewer new units, which implies reduction in environmental burdens across the board.

\section{PC end-of-life options: resell, upgrade, recycle}

Before launching into the actual energy analysis, we first elaborate on the different end-of-life options and their respective statuses of implementation.

\section{Resell}

Reselling is the practice of selling a computer to a secondary consumer when it reaches the end of its useful life with respect to the original purchaser. The case of zero price, or donation, of a computer for some social purpose such as education, is included in the definition of reselling. Secondary markets for computers are distinct in character from those of other products such as automobiles or furnishings, as computer markets are driven by the depreciation of qual- 
ity relative to newer models, as opposed to decreasing absolute quality or reliability.

As with all markets, the key to success is matching the capabilities and price of a good with the desires of the purchaser. It is important to note that many of the basic desired functions of computers, such as word processing, spreadsheets, electronic mail, and Internet browsing, can be handled very satisfactorily by older computers. Graphics and video editing work, as well as computer games, are quite another matter, but it should be noted that only one third of computer users in Japan report these as desired functions [1]. The upshot of this is that one expects that there should be quite a substantial demand for used PCs, presuming that the price is attractive compared to purchasing a new machine. Prices of used PC in the US can be quite reasonable. A refurbished system from Dell with $2 \mathrm{GHz}$ Celeron CPU, 17" CRT monitor, full software and warranty runs $\$ 460$. A previous generation system without software $(550 \mathrm{MHz}$ Pentium III, 17" monitor, 90 day warranty) run around $\$ 200$ from an Internet vendor (shipping not included, prices as of Jan. 2003). The US is an example where the used PC market has been booming, with yearly sales for 1998 estimated at near US\$6 billion and 6.4 million machines [2]. The annual growth of the secondary PC market in the US was 17 per cent [3].

\section{Upgrade}

Upgrading a computer refers to the replacement of certain components with newer versions in order to improve performance. Often, the main motivation is not dissatisfaction with the computer when running original software, rather the desire is to keep pace with the increasing demands of new operating systems and applications. The word "refurbishing" is also used in the literature; this term is avoided here as it connotes restoration to original condition, while for computers the goal is improvement of the machine's capabilities. A typical upgrade usually involves replacement of the microprocessor, memory and/or hard drive, though more extensive versions are possible. A typical upgrade is considerably less expensive than purchasing a new PC. For example, a $2 \mathrm{GHz}$ Pentium IV processor, $128 \mathrm{MB}$ RAM addition, and a $20 \mathrm{~GB}$ hard drive respectively price at $\$ 190$, $\$ 30$ and $\$ 80$ respectively in February 2003. However, not all capabilities can be easily upgraded. For instance, bus speed requires an entirely new motherboard-a fairly expensive proposition. Also, the introduction of different types of ports to interface with video (e.g. IEEE 1394) and/or peripheral buses (e.g. USB) can result in the cost for a "complete" upgrade that exceeds that of a new machine.

The extent to which upgrading is currently practiced is undocumented. Interviews with Tokyo firms specializing in computer services suggest that less than a few percent of users in Japan opt for an upgrade. These firms emphasized the necessity of user knowledge in upgrading a computer. Although an upgrade may be economically advantageous, a relatively small fraction of users are sufficiently informed to recognize this fact. As society becomes more literate in information technology, this fraction will likely increase.

\section{Recycle}

Recycling involves disassembly and/or destruction of a computer in order to recover parts and materials. The term demanufacturing is also used, which connotes an emphasis on reuse of parts over "liquidation" to recover raw materials. Recoverable raw materials fall into the categories of metals, glass, and plastics.

Metals make up about half of the weight of a typical desktop PC. The technology for recycling metals is fairly well developed, and existing facilities can recover steel, aluminum, copper, nickel, lead, zinc, gold, silver, and platinum from waste computers. The main source of the latter three precious metals are printed circuit boards, which also contain environmentally quantities of hazardous metals such as cadmium, chromium, lead, beryllium, mercury, and zinc.

Glass in cathode ray tubes (CRTs) represent $28 \%$ of the weight of a typical desktop system is difficult to recycle due to the need for deconstruction and separation of CRT components into different streams. Typically CRT glass is divided into four categories according to lead content, and then shipping to glassmakers such as Corning Asahi for use as raw material for specialized products [4].

Plastics have a $23 \%$ share of the weight of a computer system, however many technological and design barriers remain with respect to its recovery. The main obstacles are associated with the mixture qualities of plastics present in PCs [5]. A large variety of plastics are used, and there are few processes available to separate these into useable subcomponents. Techniques using a blast furnace have apparently been successful in separating out reusable polycarbonate (PC), polystyrene (PS), polyethylene (PE), and acrylonitrile-butadiene-styrene (ABS) [6]. Another approach is to build ready-to-recycle PCs according to the Design for Environment strategy.

Reusable parts from a computer are mainly electronic components, fans, transformers, wire, and disk drives. There is little data available indicating to what extent these can actually be used. One report on the economic breakdown of income from scrap electronic processing suggests that fans, transformers, wire, and disk drives make up 8 per cent of the weight of electronic waste and contributes $11 \%$ of income [7]. The reuse rate for microchips and other components on a circuit board is unknown. Circuit boards command the highest selling price (about US\$1 per $\mathrm{kg}$ ) among electronics wastes, but this is apparently due to the value of precious metals they contain rather than the components.

A study from by US National Safety Council reports that $6 \%$ of waste PCs were recycled in the 1998 [8], thus it has yet to take off in the US. Recycling of computers in the EU and countries such as Japan will dramatically increase as various legislation mandating takeback of electronics comes into effect. 


\section{Energy use in different phases of the PC life cycle}

The computer and usage pattern considered in the analysis is a desktop PC with 17" CRT monitor for a home user. Results will vary somewhat for laptop, LCD monitors and office use patterns, an issue to be discussed in the Caveats section.

\section{Production}

Estimating total energy to produce a computer requires summing of contributions from component processes, which is the domain of life cycle assessment (LCA). LCA studies of computers are decidedly scarce, and there is still not one study that gives a reasonably full description of assumptions and data used. From the outset we do not include any "black box" studies for consideration, minimal credibility requires at the very least fairly thorough descriptions of the computer assessed, system boundary of processes considered, and partial breakdown of energy use for major components of the computer (such as semiconductors, circuit boards, etc). The landmark 1993 study of the Microelectronics and Computer Technology Corporation (MCC) comes close to meeting these requirements, their result is that some $8,300 \mathrm{MJ}$ are required to produce on workstation [9]. The European Commission commissioned Atlantic Consulting/IPU to undertake a multi-parameter analysis of a PC [10]. This study meets the first criteria splendidly, as the composition of the PC is described in much detail. Unfortunately, it fails the second two criteria as no process data nor breakdown of results for different components are reported. Also, the methodology for estimating the contribution of microchips is apparently flawed. Specifically, energy use/component from the 1993 MCC report is multiplied by the number of components in a 1997 computer. The number of components varies significantly because there are many ways to achieve the same function (and total energy use) with significantly different numbers of chips.

The MCC study is dated, thus we will supplement it with estimation done via Economic Input Output Life Cycle Assessment. This method uses national data describing economic transactions between sectors (economic input-output table) and sector energy use to estimate "supply chain" energy use per dollar for different sectors in an economy [11]. The Carnegie Mellon University model using the 1997 480sector US input-output tables yields a supply-chain energy intensity for the electronic computer sector of 5.13 MJ per dollar [12]. The average selling price of a personal computer in 1998 was USD \$1,100 [13], yielding a manufacturing energy of 5,600 MJ per computer. The result using 1992 input-output table and prices yields 9,000 MJ, close to the MCC result, we presume the 1998 result provides a reasonable measure of the current energy use to manufacture a computer.
Use

Electricity consumption during the use phase requires information on usage patterns, power consumption in different modes, and lifetime of the device. A typical power use for desktop with CRT monitor is $115 \mathrm{~W}$ in active mode [14]. Given the lack of publicly available studies of usage patterns, we assume a scenario of 3 hours use per day, 365 days per year. This is likely an overestimate of active mode use for home users but hopefully accounts for some power consumption of the computer in standby mode. Both 2 and 3 years lifespan will be considered. The result for use phase consumption is $910 \mathrm{MJ}(250 \mathrm{kWh})$ for a two year lifespan and $1370 \mathrm{MJ}(380 \mathrm{kWh})$ in the case of three year lifespan.

$$
\text { Resell }
$$

The central questions regarding resold PCs are the extent to which they replace purchase of new machines and also the length of the " $2^{\text {nd }}$ lifespan". In the absence of publicly available data on this point, we assume that purchase of a used PC does indeed substitute for new demand and that the $2^{\text {nd }}$ lifespan can be either 1 or 2 years.

\section{Upgrade}

It is very reasonable to assume that upgrading replaces purchase of a new PC: in most cases it extends the lifetime of the machine for the same user. The extension of lifespan is assumed to be either 1 or 2 years.

For upgrading there is also the issue of the energy required to produce component parts. This energy will be estimated by Economic Input-output LCA. As mentioned in the previous section, a new $\mathrm{CPU}$ and $128 \mathrm{MB}$ of RAM costs USD \$220, while a new hard disc runs USD\$80. The energy intensities of the Semiconductor and Related devices and Computer Peripheral sectors are $5.6 \mathrm{MJ} / \$$ and 6.7 $\mathrm{MJ} / \$$ respectively [12]. The result is that the embodied energy in the parts for an upgrade is 1,750 MJ. This is a significant fraction of the total production energy, essential because semiconductor production uses considerable energy despite the negligible physical weight of the chips themselves [15].

$$
\text { Recycle }
$$

It is very difficult to estimate the energy balance of computer recycling due to the lack of publicly available data on recycling processes. Because of this, we are forced to resort to using a "black box" result for the base case. A study done by NEC on their own state-of-the-art system to recycle desktop PCs reports a reduction of $33 \mathrm{~kg}$ of $\mathrm{CO}_{2}$ emissions (energy equivalent $=280 \mathrm{MJ}$ ) in comparison to disposing of the machine in a landfill [6].

We also consider the possible lower and upper bounds on the energy credit/cost of computer materials recycling. For the lower bound, note that the net economics of recycling computers is negative, reputedly costing USD $\$ 10-\$ 30$ per machine. This suggests that the net energy balance could also be negative: i.e. more is expended on transport and processing of waste IT equipment than is recovered in recy- 
cled materials. This is probably not the case, because dismantling processes are usually less energy intensive than the materials production sectors they replace. However, there is no publicly available evidence to justify discarding a net energy cost for recycling computers as a worst case scenario.

It is also worth estimating the ideal upper limit on the energy credit from materials recycling of computers. This is done by assuming that transport and processing of the computer cost zero energy and that all materials can be $100 \%$ recycled. The energy embodied in the raw materials can be estimated by combining a bill of materials with the production energies. Data and calculation results appear in Tables 1 and 2.

Table 1: Energy content of materials in one desktop computer control unit (tower) (Sources: [16-20])

\begin{tabular}{|l|r|r|r|}
\hline Material & $\begin{array}{l}\text { Energy in- } \\
\text { tensity of } \\
\text { material } \\
\text { (MJ/kg) }\end{array}$ & $\begin{array}{l}\text { Amount } \\
\text { contained } \\
\text { (grams) }\end{array}$ & $\begin{array}{l}\text { Energy } \\
\text { content } \\
\text { (MJ/unit) }\end{array}$ \\
\hline steel & 59 & 6050 & 357 \\
\hline copper & 94 & 670 & 63 \\
\hline aluminum & 214 & 440 & 94 \\
\hline plastics & 84 & 650 & 55 \\
\hline Epoxy & 140 & 1040 & 146 \\
\hline Tin & 230 & 47 & 11 \\
\hline Lead & 54 & 27 & 1.5 \\
\hline nickel & 340 & 18 & 6.2 \\
\hline silver & 1570 & 1.4 & 2.3 \\
\hline gold & 84000 & 0.36 & 30 \\
\hline subtotal & & 8944 & 765 \\
\hline other & & 96 & 765 \\
\hline total & & 9040 & \\
\hline
\end{tabular}

Table 2: Energy content of materials in 17" CRT monitor (Sources: [14, 16-19])

\begin{tabular}{|l|r|r|r|}
\hline Material & $\begin{array}{l}\text { Energy } \\
\text { intensity } \\
\text { of material } \\
\text { (MJ/kg) }\end{array}$ & $\begin{array}{l}\text { Amount } \\
\text { contained } \\
\text { (grams) }\end{array}$ & $\begin{array}{l}\text { Energy } \\
\text { content } \\
\text { (MJ/unit } \\
\text { (gram }\end{array}$ \\
\hline glass & 15 & 6817 & 102 \\
\hline steel & 59 & 2830 & 167 \\
\hline copper & 94 & 700 & 66 \\
\hline ferrite & 59 & 480 & 28 \\
\hline aluminum & 214 & 240 & 51 \\
\hline plastics & 84 & 3530 & 297 \\
\hline epoxy resin & 140 & 140 & 20 \\
\hline tin & 230 & 20 & 4.6 \\
\hline lead & 54 & 593 & 32.0 \\
\hline silver & 1540 & 1.24 & 1.9 \\
\hline gold & & 0.31 & 26.0 \\
\hline Subtotal & & 15352 & 795 \\
\hline Other & & 15450 & 795 \\
\hline Total & & & \\
\hline
\end{tabular}

The energy data is a mix of results from standard LCA databases [16-18], except for gold and silver, for which no data was available. For this company-level data from the Olympic Dam mine in Australia was used assuming economic allocation for co-products [19]. The bills of materials for desktop control unit and monitor are from references [20] and [14] respectively. The main result is that the energy content of raw materials in a desktop PC is 1,560 MJ, about $28 \%$ of total production energy. It is impossible for the energy credit from recycling raw materials to exceed this amount.

\section{Collecting energy results}

The values for energy use and lifespan are summarized in Table 3, along with the definition of notation to be used in the next section. Note that landfilling a computer is not included in the list, apparently its energy cost is negligible compared to other factors [14].

Table 3: Energy and other parameter values for desktop computer (home use)

\begin{tabular}{|l|c|r|}
\hline \multicolumn{1}{|c|}{ Life cycle stage } & $\begin{array}{c}\text { Nota- } \\
\text { tion }\end{array}$ & \multicolumn{1}{c|}{ Value } \\
\hline Production & $\mathrm{E}_{\mathrm{M}}$ & $5600 \mathrm{MJ}$ \\
\hline Use $\left(2\right.$ year $1^{\text {st }}$ lifespan) & $\mathrm{E}_{\text {Use }}$ & $910 \mathrm{MJ}$ \\
\hline Use $\left(3\right.$ year $1^{\text {st }}$ lifespan) & $\mathrm{E}_{\text {Use }}$ & $1360 \mathrm{MJ}$ \\
\hline $2^{\text {nd }}$ lifespan & $\mathrm{E}_{\mathrm{U}}$ & $1-2$ years \\
\hline $\begin{array}{l}\text { Upgrade } \\
\text { (energy to make parts) }\end{array}$ & $\mathrm{E}_{\mathrm{R}}$ & $\begin{array}{r}-280 \mathrm{MJ} \\
\text { (theoretical limit. } \\
-1560 \mathrm{MJ})\end{array}$ \\
\hline Recycle & & $\begin{array}{r}1750 \mathrm{MJ} \\
\end{array}$
\end{tabular}

\section{EVALUATING ENVIRONMENTAL EFFECTIVENESS OF RESELL, UPGRADE, AND RECYCLE OPTIONS}

\section{Model definition}

The basis of the analysis is a simple mathematical model that represents the relationship between life cycle energy use and the degree of implementation of end-of-life options. Let $r_{1}, r_{2}$, and $r_{3}$ be the implementation rates (\%) of reselling, upgrading, and recycling for a set of computers. $x_{1}$ and $\mathrm{x}_{2}$ are the ratios of second lifespan over $1^{\text {st }}$ lifespan for resell and upgrade option. The life cycle energy (LCE) associated with a set of computers can be written as

$$
L C E=E_{M}+E_{U s e}-x_{1} r_{1} E_{M}-x_{2} r_{2}\left(E_{M}-E_{U p}\right)+r_{3} E_{R} \text {. }
$$

The central assumption in this model is that reselling or upgrading a computer will replace the need for a new machine for the span of its $2^{\text {nd }}$ life, after which that user has a new machine. This probably describes the case for upgrading fairly accurately, but is less certain for used machines. 
This model also assumes no interaction between the rates of implementation of different options. This is not true in general but should hold when implementation rates are small.

The effectiveness of end-of-life options in saving energy can be quantitatively modeled using the above formula. The effectiveness coefficient (EC) is defined to be the percentage savings in life cycle energy given 10 per cent implementation of a given end-of-life option. In mathematical terms, the effectiveness coefficient of option $\mathrm{j}$ (where $1=$ resell, $2=$ upgrade, $3=$ recycle) becomes

$$
\mathrm{EC}_{\mathrm{j}} \equiv \frac{\Delta \mathrm{LCE}}{\mathrm{LCE}}=\frac{\frac{\partial \mathrm{LCE}}{\partial r_{j}} \cdot 10 \%}{\mathrm{LCE}}
$$

\section{Results}

Numerical values of the effectiveness coefficients are calculated using the values in Table 3 , the results of which are shown in Table 4.

Table 4: Fraction of life cycle energy saved given that $10 \%$ of computers are resold, upgraded, or recycled

\begin{tabular}{|c|c|c|c|}
\hline Scenario & $\begin{array}{l}\mathrm{EC}_{1} \\
\text { (resell) }\end{array}$ & $\begin{array}{l}\mathrm{EC}_{2} \\
\text { (upgrade) }\end{array}$ & $\begin{array}{l}\mathrm{EC}_{3} \\
\text { (recycle) }\end{array}$ \\
\hline Base case & $8.6 \%$ & $5.2 \%$ & $0.43 \%$ \\
\hline $\begin{array}{l}\text { Long } 1^{\text {st }} \text { life }(3 \mathrm{yr}) \text {, } \\
\text { short } 2^{\text {nd }} \text { life }(1 \mathrm{yr})\end{array}$ & $2.7 \%$ & $1.8 \%$ & $0.40 \%$ \\
\hline $\begin{array}{l}\text { Recycling at } \\
\text { theoretical limit } \\
\left(E_{R}=-1,560 \mathrm{MJ}\right)\end{array}$ & - & - & $2.4 \%$ \\
\hline
\end{tabular}

For the base case, reselling and upgrading computers are some 20 and 12 times more effective at saving life cycle energy use than recycling. Other scale-driven environmental impacts should also show a similar difference. The results shows a dramatic reduction in the benefit of reselling and upgrading as the $2^{\text {nd }}$ lifespan gets smaller, though they still save more energy than recycling even given pessimistic assumptions. The conclusion to be drawn is that the emphasis given to upstream waste management according to the "3Rs" should also be given to computers.

The results can also be understood from an intuitive perspective. Since computers are high-tech goods, it is natural to expect that the bulk of the production energy is embodied in the form of the product rather than in the raw materials. As the rapid tech cycles reduce the reusability of the parts themselves, recycling becomes primarily focused on raw materials. However, as most of the energy investment is in the form of the product, not its materials content, extension of life span naturally leads to greater savings than recycling.

\section{CAVEATS}

The discussion of caveats to the results can be divided into data quality, scenarios considered, and issues related to underlying model used. Data quality is clearly important, much uncertainty remains regarding energy use for different life cycle stages for computers, especially for recycling. In terms of scenarios considered, the analysis treated only the case of desktop computers for home use. There are many office users (for which use phase consumption is much higher) and also laptop computers are increasing in popularity (lower use phase electricity consumption). Although recycling of parts is apparently quite limited, its inclusion in the recycling scenario would improve the estimation of energy payback. The model itself assumes no relation between implementation of resell, upgrade, and recycling, in fact this should be the case. More importantly, the model should incorporate overall user demands for different computing services and relate the end-of-life options to the structure of this demand. Such a description would clarify the upper limits to implementation of different options and also how far current implementation is from these limits. However, such a model (engine) requires data (fuel) that does not yet exist.

However, these caveats should be considered in the context of the objective of the analysis. The purpose here is only to compare end-of-life options at the level of order of magnitude. From this perspective, the results should be robust: reselling and upgrading are very effective options for reducing life cycle impacts of computers and thus should pursued at least as aggressively as recycling.

\section{ACKNOWLEDGMENTS}

This research was financially supported by the Japan Foundation for Global Partnership and the Takeda Foundation.

\section{REFERENCES}

[1] Nikkei Market Access Annual IT basic data 600 (Nikkei Maketto Akusesu nenkan IT kihon deta 600), Nikkei Publishing: Tokyo (2000) (in Japanese).

[2] J. Rosa, "Like magic, old PCs reappear", Computer Reseller News 829, 47 and 54, Feb 15 issue (1999).

[3] "Used PC market continues to evolve: IDC review and forecast", Computer Dealer News 14 (16), 20-21 (1998).

[4] P. Dillon, "Potential Markets for CRTs and Plastics from Electronics Demanufacturing: an Initial Scoping Report”, Technical Report \#6, Chelsea Center for Recycling and Economic Development, University of Massachusetts (1998) (URL: http://www.chelseacenter.org/Publications1.asp, last accessed Feb. 2003). 
[5] S. Das, S. Matthew, "Characterization of Material Outputs from and Electronics Demanufacturing Facility," 1999 IEEE International Symposium on Electronics and the Environment, IEEE, New Brunswick, New Jersey (1999).

[6] H. Takesue, "Assessment of Environmental Impact in the Recycling of Communications Equipment", in Proceedings of the Fourth International Conference on Ecobalance, Society for Non-Traditional Technology: Tokyo, 555-558 (2000).

[7] J. Pepi, "University of Massachusetts Amherst Scrap Electronics Processing", Technical Report \#7, Chelsea Center for Recycling and Economic Development, University of Massachusetts (1998) (URL: http://www.chelseacenter.org/Publications1.asp, last accessed Feb. 2003).

[8] D. Amore, "Study Finds Computer Recycling Not Clicking", Waste Age 30(12), 14-15 (1998).

[9] Environmental Consciousness: A Strategic Competitiveness Issue for the Electronics and Computer Industry, Microelectronics and Computer Technology Corporation (MCC), Austin, Texas (1993).

[10]LCA Study of the Product Group Personal Computers in the EU Ecolabel Scheme, version 1.2.1, Atlantic Consulting and IPU, London (1998).

[11]C. Bullard, R. Herendeen, "The energy cost of goods and services". Energy Policy. December. pp. 268-277 (1975).

[12] Economic Input-Output Life Cycle Assessment website, Carnegie Mellon University, Green Design Initiative: Pittsburgh (2003) (URL: http://www.eiolca.net/, last accessed Feb. 2003).
[13] J. Carlton, "PC Demand is Offset by Shrinking Prices", Wall Street Journal, B6, Oct. 26 (1998).

[14] S. Miyamoto, M. Tekawa, A. Inaba, "Life Cycle Assessment of Personal Computers for the Purpose of Design for Environment", Energy and Resources 19 (1), 75-80 (1998) (in Japanese).

[15]E. Williams, R. Ayres, M. Heller, "The 1.7 kg Microchip: energy and chemical use in the production of semiconductors", Environmental Science \& Technology 36 (24), 5504-5510, Dec. 15 (2002).

[16] Boustead Model for life cycle inventory calculations, version 4.2, Boustead Consulting: West Sussex, UK (1999).

[17] Economic Inventory of Packaging Database (BUWAL 250), Bundesamt für Umwelt, Wald und Landschaft (Swiss Federal Office of Environment, Forests and Landscape and the Swiss Packaging Institute): Zurich (1996).

[18] IDEMAT database, Design for Sustainability Program, Delft University of Technology (2001).

[19] "Greenhouse Challenge: Summary Report 1998", WMC Resources Ltd. Southbank, Australia (1998).

[20] Y. Shimoda, N. Yoshida, N. Yasuda, T. Shirakawa, T. Morioka, "LCA for Personal Computer in Consideration of Various use and Upgrading", in Proceedings of the Third International Conference on Ecobalance, Society for Non-Traditional Technology: Tokyo, 251254 (1998). 